\title{
Benign spotted bones: a diagnostic dilemma
}

\author{
Gina Di Primio MD
}

See related practice articles by by Hii and Tan, page 460 and Padín-Paz and Díaz-Peromingo, page 461

Competing interests:

Gina Di Primio has received

financial reimbursement

from the Ottawa Hospital and Region Imaging

Associates and honoraria for lectures on continuing medical education.

This article has been peer reviewed.

Correspondence to:

Dr. Gina Di Primio,

gdiprimio@ottawahospital .on.ca

CMAJ 2011. DOI:10.1503 /cmaj.091740

\section{The case}

A young woman presented to the emergency department with acute knee pain after a minor fall. Radiographs showed no evidence of fracture or joint effusion, but scattered periarticular sclerotic foci of variable size were noted in the femur and tibia (Figure 1). These lesions were recognized by the radiologist as typical for osteopoikilosis.

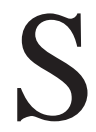
potted bones associated with benign conditions can have a very typical radiographic appearance and distribution; however, ambiguity in this appearance or a history of malignant disease can lead to diagnostic uncertainty and the need for further investigation. This clinical primer will focus on one characteristic benign condition, osteopoikilosis, its relevant differential diagnosis and workup.

Osteopoikilosis was first described in 1915 by Albers-Schönberg as a sclerosing bone dysplasia of unknown cause. ${ }^{1}$ It is also referred to as spotted bones or osteopathia condensans disseminata. A diagnosis of exclusion, cases may be underreported. Prevalence in the general population is unknown, but an older retrospective review reported an estimated prevalence of 1 in $50000 .^{2}$ The lesions have been described in all age groups, and although prevalence studies have shown a higher frequency among men, the apparently unequal sex distribution may be a result of referral bias in the literature (men are more likely

\section{- KEY POINTS}

- Osteopoikilosis is an uncommon, benign, asymptomatic disorder and is often an incidental finding.

- A characteristic radiograph will show multiple round or oval sclerotic lesions in a periarticular distribution.

- No further investigation is required if the patient is otherwise healthy and there is no suspicion of systemic or metastatic disease.

- Scinitigraphy with technetium $99 \mathrm{~m}$ is helpful in ruling out disorders that are of greater concern.

than women to present to hospital with traumatic injuries requiring radiologic investigation). ${ }^{2,3}$

Osteopoikilosis exists in hereditary (autosomal dominant transmission) and sporadic forms ${ }^{4-7}$ and is one of several bone dysplasias characterized by defective endochondral bone formation. ${ }^{5}$ Endochondral ossification refers to the formation of the long and flat bones, which begins from a primitive hyaline cartilaginous model. This process is in contrast to intramembranous ossification, which refers to direct transformation of condensed mesenchymal cells into cortical bone without a cartilaginous phase, as is typically seen in the formation of the skull bones.

Most reported cases of osteopoikilosis are identified during the investigation of unrelated problems in which there is no clinical history suggestive of either malignant or systemic disease. ${ }^{89}$ In such situations, no further workup is necessary. The characteristic radiologic feature is multiple, punctate, sclerotic, round or oval foci symmetrically distributed in a predominantly periarticular fashion within the epiphyseal and metaphyseal regions. ${ }^{89}$ In the three patients described in this issue, most of the sclerotic foci are $1-2 \mathrm{~mm}$, although some lesions measure up to $10 \mathrm{~mm}$. Although further investigation is unnecessary in typical osteopoikilosis, when radionuclide bone scans are performed, their results are negative. In clinical and radiologic follow-up of osteopoikilosis, the lesions remain stable.

Osteopoikilosis is typically an asymptomatic incidental finding, but it can be associated with other diseases. Most importantly, it must be differentiated from sclerotic metastases and other sclerosing dyplasias.

\section{Workup of sclerotic lesions of bone}

Sclerotic lesions of bone are areas of increased bone density seen on plain radiographs. When viewing an image showing spotted bones, it is necessary to consider the following three ele- 
ments: the appearance of the spots, their number, and their location and distribution.

\section{Appearance and number}

As mentioned previously, the characteristic radiologic feature in osteopoikilosis is multiple, punctate, sclerotic, rounded or oval foci. In benign enostosis, or bone islands, which also have sclerotic rounded lesions, the peripheral margins tend to blend or merge with the underlying normal trabecula (Figure 2). These lesions are typically small $(<1 \mathrm{~cm})$ and frequently isolated. Although the lesions in enostosis are usually round or oval, their shape is not specific. If the lesions are larger than $1 \mathrm{~cm}$, other sclerotic bone conditions or lesions must be considered, despite the characteristic appearance of the peripheral margins.

If sclerotic lesions are large or numerous, the diagnosis of osteopoikilosis or enostosis is questionable. In addition, bone islands should be blandly homogeneous, as they represent a hamartoma (i.e., cortical bone where medullary bone should be). Nonhomogeneous or multiple lesions are cause for concern, as they may indicate osteoblastic activity related to an underlying marrow-replacing disease such as metastasis (Figure 3).

\section{Location and distribution}

The multiple benign lesions of osteopoikilosis tend to have a characteristically symmetrical periarticular distribution within the epiphyseal and metaphyseal regions of the axial and appendicular skeleton that is virtually diagnostic of the condition. Osteopoikolosis has not been described in the skull.

Metastases tend to be more frequent in the pelvis and spine. Metastatic disease can affect any bone, but it predominates in the axial skeleton, is rarely seen below the knee or elbow and tends not to follow a periarticular distribution.
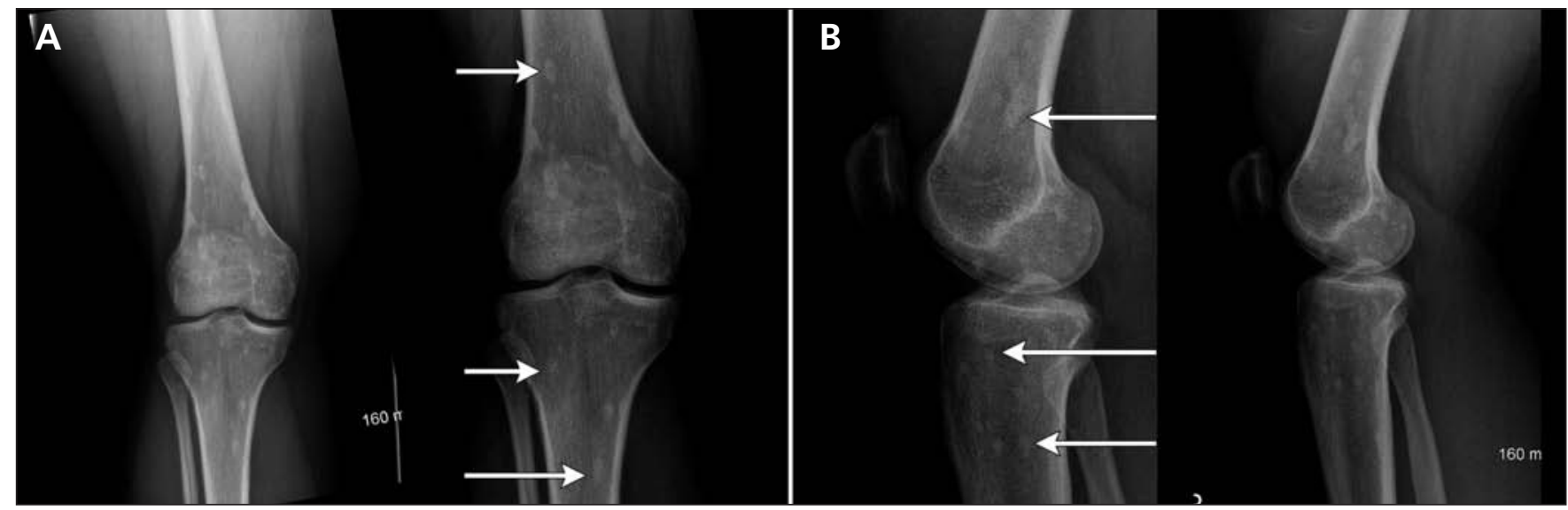

Figure 1: (A) Anteroposterior and (B) lateral radiographs of the right knee in a young woman after a fall. Sclerotic foci of variable size (arrows) appear in the femur and tibia. Note the periarticular distribution and predominant meta-epiphyseal location (sites of endochondral bone formation) characteristic of osteopoikilosis.
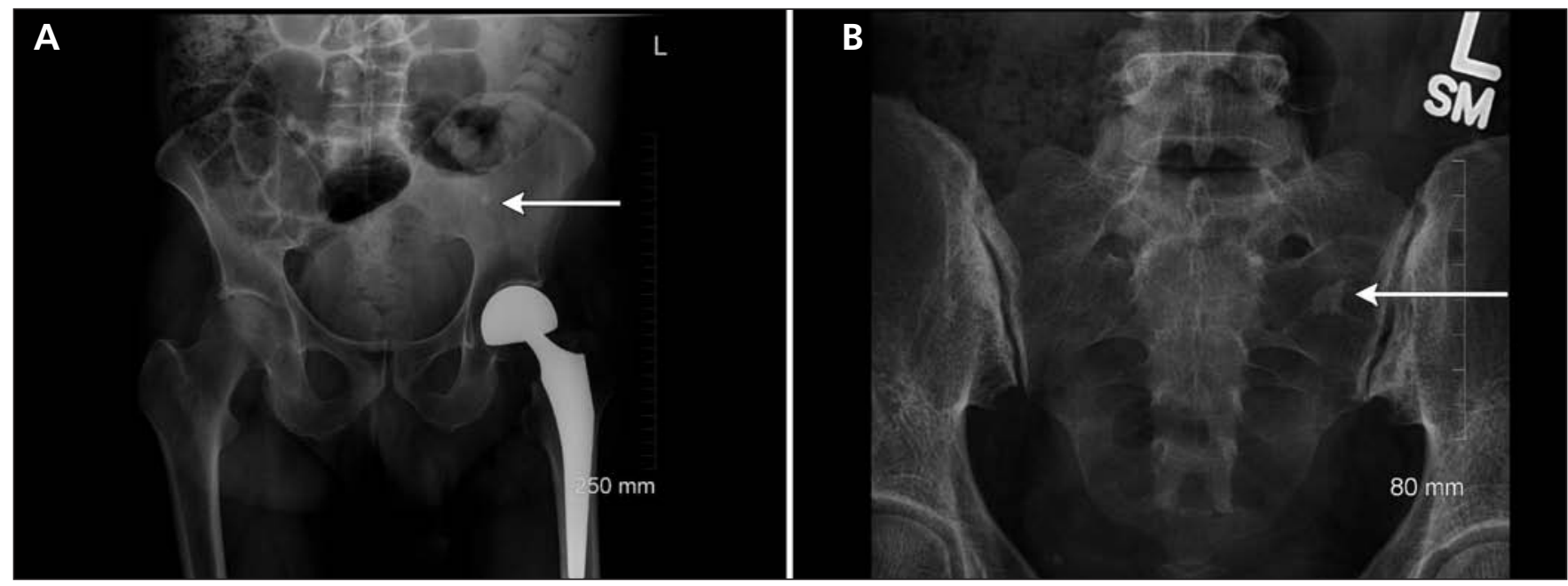

Figure 2: (A) Anteroposterior view of the pelvis showing a single sclerotic focus in the left iliac bone (arrow) typical of a bone island or enostosis. (B) Anteroposterior view of the sacrum showing a single dense sclerotic focus in the left ala. Spiculated margins (arrow) merge with underlying normal trabeculae, which is characteristic of bone islands. 
Other systemic conditions, such as mastocytosis and tuberous sclerosis, can present with multiple lesions and in many different locations. Sarcoidosis can involve the spine, but it does not involve the skull.

\section{Additional testing}

As with many radiologic interpretations, the patient's clinical history is highly relevant to the workup of bone lesions. The most straightforward diagnosis of osteopoikilosis can be made when the characteristically benign-looking periarticular spots are found incidentally in an otherwise healthy person or in a patient presenting with a traumatic injury. Difficulty occurs when patients present for other reasons, such as joint pain, as described in a number of case reports. ${ }^{10-12}$

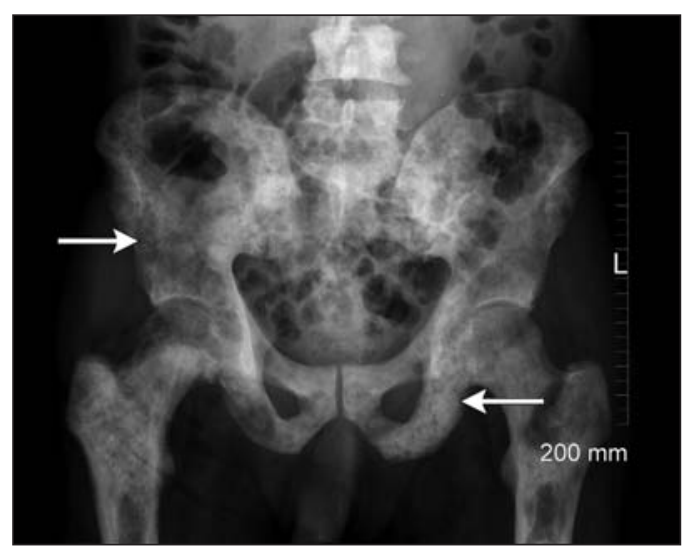

Figure 3: Anteroposterior view of the pelvis showing patchy, poorly defined areas of sclerosis over the entire pelvis and proximal femora. Subtle, more focal areas and diffuse areas of sclerosis are visible. This pattern is most typical of sclerotic bone metastasis (e.g., as a result of prostate cancer in this patient). A subtle underlying pattern of small, rounded lesions can also be seen (arrows).
In these situations, a review of previous imaging is essential to show that the lesion has remained stable over time. Correlation with a radionuclide technetium-99m bone scan can be performed when previous images are not available.

Although there have been reports describing uptake of ${ }^{99 \mathrm{~m}} \mathrm{Tc}$ in patients with osteopoikilosis and enostoses, such false-positive results are uncommon and are usually seen only in patients with larger lesions. ${ }^{12-17}$ The uptake may be due to active remodeling of the bone, i.e., a process similar to the formation of calluses. ${ }^{15}$

Although uptake of ${ }^{99 \mathrm{~m}} \mathrm{Tc}$ is unusual in osteopoikilosis and bone islands, it is commonly observed in connection with metastasis (Figure 3), sarcoidosis, mastocytosis and tuberous sclerosis. ${ }^{10,18-20}$ Such conditions are associated with systemic illness in addition to their radiologic manifestations, and their appearance is usually clinically overt by the time skeletal changes occur. ${ }^{18-20}$

\section{Other bone dysplasias}

In addition to osteopoikilosis and enostosis, dysplasias of endochondral bone formation include osteopetrosis (Albers-Schönberg disease), pycnodysostosis and osteopathia striata (Voorhoeve disease), each with varying radiologic appearances (Table 1). ${ }^{5,6}$

Enostosis histopathologically and radiographically most closely resembles osteopoikilosis. As mentioned previously, the difference is that bone islands can be isolated and small. If multiple, they are usually scattered and do not display a characteristic periarticular distribution. Histopathologically, the lesions consist of compact, markedly hypertrophied trabeculae composed of lamellar osseous tissue. ${ }^{21}$ Osteons within a bone island are not regularly

Table 1: Dysplasias of endochondral bone formation ${ }^{6,7}$

\begin{tabular}{|c|c|c|c|}
\hline Diagnosis & Genetics of inheritance & Distinctive radiologic features & Distinctive clinical features \\
\hline Osteopoikilosis & $A D$ or sporadic & $\begin{array}{l}\text { Sclerotic, rounded or oval foci } \\
\text { with a typically periarticular } \\
\text { distribution }\end{array}$ & $\begin{array}{l}\text { Asymptomatic if sporadic; AD } \\
\text { form is associated with } \\
\text { dermatofibrosis lenticularis } \\
\text { disseminata }\end{array}$ \\
\hline Enostosis (bone island) & None (not inherited) & $\begin{array}{l}\text { Sclerotic, rounded or oval foci } \\
\text { (scattered) }\end{array}$ & Asymptomatic \\
\hline Osteopetrosis & AR (lethal) or AD (adult form) & $\begin{array}{l}\text { Diffuse sclerosis or bone-within- } \\
\text { bone pattern }\end{array}$ & $\begin{array}{l}\text { Variable anemia and increased } \\
\text { risk of fractures }\end{array}$ \\
\hline Pycnodysostosis & $A R$ & $\begin{array}{l}\text { Diffuse sclerosis (similar to } \\
\text { osteopetrosis) }\end{array}$ & $\begin{array}{l}\text { Dwarfism, mandibular } \\
\text { hypoplasia, short fingers }\end{array}$ \\
\hline Osteopathia striata & $A D$ or sporadic & $\begin{array}{l}\text { Linear areas of sclerosis with } \\
\text { periarticular distribution }\end{array}$ & Asymptomatic \\
\hline $\begin{array}{l}\text { Osteopathia striata with } \\
\text { cranial sclerosis }\end{array}$ & $A D$ & $\begin{array}{l}\text { Linear areas of sclerosis with } \\
\text { periarticular distribution }\end{array}$ & Cranial nerve dysfunction \\
\hline
\end{tabular}




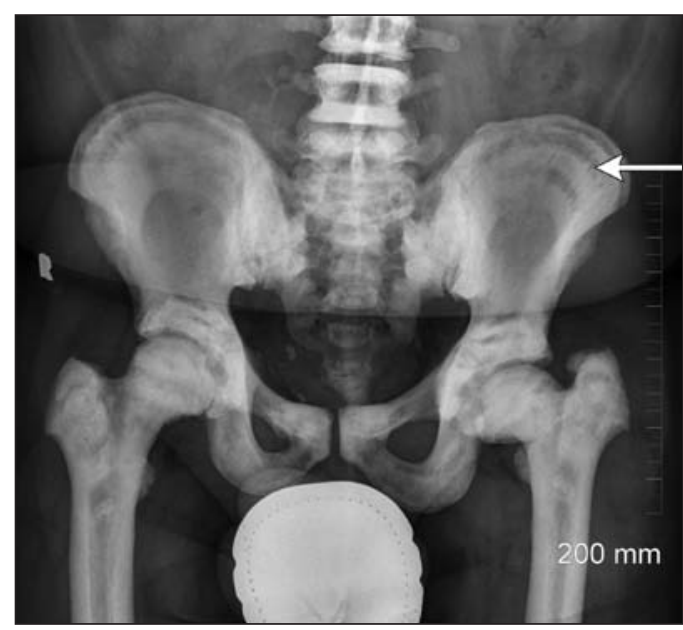

Figure 4: Anteroposterior view of the pelvis showing a pattern of layered sclerosis (arrow) described as bone within bone and characteristic of osteopetrosis.

oriented and contain well-vascularized canals surrounding narrow rings of lamellae, but which are empty of osteoclasts and osteoblasts. ${ }^{21}$

Both osteopetrosis (Figure 4) and pycnodysostosis have a very different radiographic appearance from osteopoikilosis; the lesions appear in a more diffuse pattern of sclerosis, rather than spotted or rounded. ${ }^{5}$ These patients also have severe systemic manifestations.

Osteopathia striata (Figure 5) also has a different appearance. The sclerotic areas within the bone are neither round nor oval. Instead, they are linearly striated and periarticular in distribution. Clinical manifestations of this disorder are subtle or nonexistent. Histopathologic and biochemical studies are able to differentiate osteopetrosis and pycnodysostosis from osteopoikilosis, but little pathologic data are available on osteopathia striata. ${ }^{6.11114}$ Fortunately, all of these disorders can be diagnosed and differentiated readily by their radiologic features.

Genetic links have been made between osteopoikilosis and Buschke-Ollendorff syndrome (also known as dermatofibrosis lenticularis disseminata), a condition in which osteopoikilosis is specifically, but not strictly, associated with dermatalogic lesions..$^{22}$

\section{Summary}

The discovery of bone spots on a radiograph is often disturbing, and benign conditions need to be differentiated from indicators of serious disease. Osteopoikilosis is one of several uncommon benign variants of bone formation that must be distinguished from more worrisome disorders, most notably osteoblastic metastases. This differentiation can be done on the basis of the lack of internal architecture, irregular margins, the periarticular distribution and relative sparing of the skull.

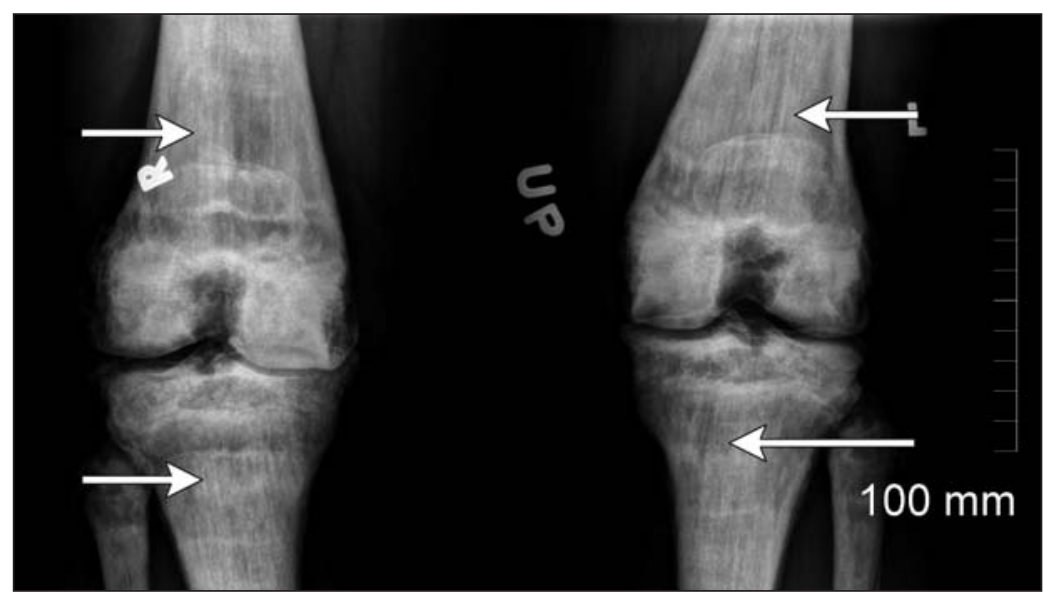

Figure 5: Anteroposterior view of a patient's knees showing a pattern of diffuse sclerosis similar to that seen in osteopetrosis. However, vertical striations (arrows) shown in the distal femora and proximal tibia are consistent with the pattern seen in osteopathia striata.

\section{References}

1. Albers-Schönberg H. Eine seltene, bischer nicht bekannte strukturanomalie des skelettes. Fortschr Roentgenstrb 1915;73:174-5.

2. Jonash E. 12 falle von soteopoikilie. Fortschr Roentgenstr $1955 ; 82: 344-53$

3. Szabo AD. Osteopoikilosis in a twin. Clin Orthop Relat Res 1971; 79:156-63.

4. Melnick JC. Osteopathia condensas disseminata (osteopoikilosis) Study of a family of 4 generations. Am J Roentgen 1959;82:344-53.

5. Vanhoenacker FM, De Beuckeleer LH, Van Hul W, et al. Sclerosing bone dysplasias: genetic and radioclinical features. Eur Radiol 2000;10:1423-33.

6. Hellemans J, Preobrazhenska O, Willaet A, et al. Loss of function mutation in LEMD3 result in osteopoikilosis, Buschke-Ollendorff syndrome and melorheostosis. Nat Genet 2004;36:1213-8.

7. Benli IT, Akalin S, Boysan E, et al. Epidemiologial and radiological aspects of osteopoikilosis. J Bone Joint Surg Br 1992;74:504-6.

8. Padín-Paz EM, Díaz-Peromingo JA. Osteopoikilosis in the knee. CMAJ 2011;183:461.

9. Hii $\mathrm{CH}$, Tan $\mathrm{CK}$. Osteopoikilosis in the pelvic region. CMAJ 2011;183:460.

10. Canade A, Costantini AM, Reale F, et al. Reasoned approach to multiple osteosclerotic lesions. combined diagnostic imaging in a case of osteopoikilois. Rays 2005;30:273-7.

11. Waddel C, Demos TC, Lomasney L, et al. Radiologic case study. Orthopedics. ProQuest Health and Medical Complete 2005;8:720.

12. Borman P, Ozoran K, Aydog S, et al. Osteopoikilosis: report of a clinical case and review of the literature. Joint Bone Spine 2002;69:230-3.

13. Tong ECK, Samii M, Tchang F. Bone imaging as an aid for the diagnosis of osteopoikilosis. Clin Nucl Med 1988;13:816-9.

14. Wadhwa S, Mansberg R. Abnormal bone scan in osteopoikilosis. Clin Nucl Med 1999;24:71-2.

15. Mungovan JA, Tung GA, Lambiase RE, et al. Tc-99m MDP uptake in osteopoikilosis. Clin Nucl Med 1994;19:6-8.

16. Appenzeller S, Castro GRW, Coimbra IB. Osteopoikilosis with abnormal bone scan - long term follow-up. J Clin Rheumatol 2007;13:291-2

17. Serdaroglu M, Capkin E, Ucuncu F, et al. Case report of a patient with osteopoikilosis. Rheumatol Int 2007;27:683-6.

18. Delsignore JL, Dvoretsky PM, Hicks DG, et al. Mastocytosis presenting as a skeletal disorder. Iowa Orthop J 1996;16:126-34.

19. Nijjar SS, Leslie WD. A case of skeletal sarcoidosis imitating skeletal metastases on bone scintigraphy. CMAJ 2008;178:153-4.

20. Bell DG, King BF, Hattery RR, et al. Imaging characteristics of tuberous sclerosis. AJR Am J Roentgenol 1991;156:1081-6.

21. Caballes RL, Caballes RA Jr. Polyostotic giant enostoses with strongly positive radionuclide bone scan. Ann Diagn Pathol 2004;8:247-51.

22. Mumm S, Wenkert D, Zhang X, et al. Deactivating germline mutation in LEMD3 cause osteopoikilois and Buschke-Ollendorff syndrome, but not melorheostosis. J Bone Miner Res 2007;22:243-50.

Affiliation: From Diagnostic Imaging, the Ottawa Hospital, Ottawa, Ont. 